\title{
ENTREVISTA A HILARY PUTNAM
}

\section{1. ¿Hay una actualidad de Descartes?}

Bien, yo he escrito en la obra que considero más importante de estos últimos dos años y que apareció monográficamente en el Journal of Philosophy, mis Dewey Lectures, las cuales constituyen fundamentalmente un ataque contra el modo de pensar cartesiano, que es necesario, o sea, que, básicamente, no hemos superado al menos algunos aspectos de la filosolia de Descartes. Descartes ha marcado el programa de toda la filosofia moderna y, no en vano, el mismo término de "filosofia moderna" siempre lia significado "filosofia después de Descartes", lo cual me parece ser suficiente testimonio de su importancia, incluso cuando no se está de acuerdo con él. Hace doscientos años que todo el mundo habla de superar el modo de pensar de Descartes, pero éste sigue sindo el punto de referencia y aún no hemos encontrado la manera correcla de superarlo.

\section{2. ¿Descartes es un pensador francés o un pensador de lo universal?}

No me gustan las dicotomias. Todo filósofo se ve influenciado por su propia lengua, su propio pais, su propia historia, pero considero que la filosofia es por su naturaleza misma una empresa universal. Creo que el objetivo de la reflexión filosófica es universal, no sólo por cómo habla sino respecto aquello de lo que habla.

3. ¿Cuál es el papel de Descartes en el advenimiento científico de la modernidad?

Descartes juega un papel fundamental. Su fisica no fue una fisica con éxito, en el sentido por ejemplo de que su teoría de los vórtices no funcionaba mientras que si lo hacia la mecánica de particulas de Newton. Aunque, de hecho, cuando Newton estudia a Descartes, pone a prucba deducciones y argumentos de manera bien precisa y, ciertamente, abunda en algunas ideas centrales de Descartes. La ley de la inercia, por ejemplo, se sostiene sobre la idea cartesiana de que el movimiento de la inercia es una línea recta, y esto, que era el núcleo de la mecánica cartesiana, es igualmente el núcleo de la mecánica newtoniana.

Creo que a menudo corremos el riesgo de pasar por alto la mayor contribución del pensamiento cartesiano. El modo en que Descartes modela la filosofia moderna implica, primordialmente, su imagen de la mente. La imagen cartesiana de la mente se encuentra bien próxima a la aristotélica, en un intento que considero de retorno a la imagen de la mente de Aristóteles sin recavar en el aspecto terapeútico; es una imagen de la mente situada en el seno del individuo, como un teatro mental privado; las sensaciones e ideas de cada persona tienen su lugar en un teatro mental privado. Esta imagen es exactamente la que provoca la enome oposición entre idealismo y realismo; una oposición que la dado y sigue dando lugar a la dialéctica vertebradora de toda filosofia moderna. Los empiristas sólo fueron capaces de reclinzar esta imagen de la mente y ello, a costa de instaurar un increible idealismo subjetivo. Alora nos manifestamos en contra de este idealismo subjetivo y jaqui estamos de nuevo! Probablemente, todo el sentido de la laguna entre la mente y el mundo sea la más firme herencia cartesiana. Creo que va a ser necesario recoger aquellas intuiciones más relevantes de la tradición continental, del mismo Descartes, de Hegel... asi como de Wittgenstein, de Austin, del modo de pensar de la filosofia analilica, para hacer posible la edificación de una imagen, de un paradigma alternativo desde donde pensar la relación entre la mente $y$ el mundo. 
4. ¿Cuál es el papel de Descartes en el advenimiento politico de la modernidad?

En el aspecto político, la influencia de Descartes no me parece exclusiva de Descartes, puesto que la deriva obviamente de la fisica, asi como del reto planteado por el sistema escolástico. Por supuesto, juega un papel en la Ilustración y, en ese sentido, Descartes y su filosofia son una de las fuentes de la llustración. En ese sentido Descartes sigue también a Bacon un gran filósofo y se sirve de él con conceptos como lo puramente a priori o la mecánica puramente racional, sin negar en ningún caso la gran importancia de los experimentos. Considero, de todos modos, que una gran parte de la significación política de Descartes yace en su estilo literario; él y Rosseau crearon la lengua francesa moderna, puesto que no la heredaron tal y como nosotros la conoccmos ahora, sino que, en cierto modo, jla hicieron!

\section{5. ¿Hay una urgencia de Descartes tras la quiebra de la Modernidad?}

Creo que el post-modernismo, al menos el representado por Derrida no comporta una superación del cartesianismo sino, contrariamente, una versión aún más radical del mismo. Creo que la idea de que el mundo es en cierto modo presente para nosotros es correcta y soy consciente de que, afirmando esto, para Derrida soy culpable en términos de "metafisica de la presencia": pero es que el mismisimo concepto de "metafisica de la presencia", asume algo que nos Ilega desde la tradición cartesiana, a saber, que todo conocimiento que es de alguna manera falible tiene que ser mediado o "referido", como el mismo Derrida diria. La misma idea o imagen del conocimiento como algo que hay entre nosotros y el conocimiento es la idea del texto o de la finalidad del texto, del texto en sus modos operacionales, de las lecturas del texto, etc. Pero el movimiento fundamental es esencialmente una versión todavía más radical de la forma moderna del escepticismo según es descrito por Hegel, a saber, como escepticismo dogmútico. Hegel tiene toda la razón y el post-modernismo es un dogmatismo. Creo que debemos superar a Derrida de un modo correcto y no sencillamente proclamando que ha sido superado. 